Rapid Reviews COVID-19

\title{
Reviews of "Comparison of
} infection control strategies to reduce COVID-19 outbreaks in homeless shelters in the United

\section{States: a simulation study"}

\section{Gregory Karelas ${ }^{1}$, Fiona Walsh ${ }^{2}$}

${ }^{1}$ Columbia University Mailman School of Public Health, Health Policy and Management, USA,

${ }^{2}$ Principal Consultant, Mesurado Cooperative, USA

Published on: Nov 06, 2020

DOI: $10.1162 / 2 \mathrm{e} 3983 f 5.70446 \mathrm{~d} 36$

License: Creative Commons Attribution 4.0 International License(CC-BY 4.0). 
To read the original manuscript, click the link above.

Summary of Reviews: Reviewers find this study a generally reliable and important contribution to understanding infection control strategies in a high-risk setting, though several assumptions in the model could be clarified.

Reviewer 1 (Gregory Karelas) | प्म००

Reviewer 2 (Fiona Walsh)

\section{RR:C19 Strength of Evidence Scale Key}

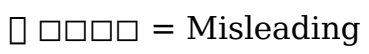

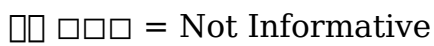

प्रा पि = Potentially Informative

प्राप्र = Reliable

प्राप्र = Strong

To read the reviews, click the links below. 